\title{
Nano-Gene-Delivery: Overcoming One of the Major Challenges in Gene Therapy
}

\section{Sonia Trigueros* \\ Department of Zoology, University of Oxford, Englandc}

*Corresponding author: Sonia Trigueros, Oxford Martin Programme of Nanotechnology. Department of Zoology University of Oxford, Oxford, OX1 3PS, England, Email: sonia.trigueros@zoo.ox.ac.uk

Submission: 泟June 12, 2018; Published: 笽July 25, 2018

\section{Mini Review}

Adeno-associated virus vectors (AAVs) have been used in several gene-therapy protocols since they are non-integrative and less immunogenic compared to retroviruses or lentiviruses, but several concerns such as DNA size capacity, high production costs, probability of immunogenicity, and their invasive route of administration has fostered the design of non-viral vectors as an alternative. Non-viral vectors are less immunogenic, do not induce major inflammatory responses, are safe and easy to produce in large scale. Nonetheless, their main limitation still is the lower cell transfection efficiency. Non-viral particles can be divided into three groups, lipoplex particles containing lipid molecules, polyplex particles based on polycations (sugars, proteins or other polymers), and inorganic nanostructures. Gene-delivery by synthetic vectors involves the endocytosis of DNA-complexes, endosomes escape, and diffusion of non-complexed DNA through the cytosol to reach the nucleus.

\section{Nanotechnology on gene delivery}

Sereval nanomaterials are being develop for gene-delivery use. They are considered into the group of non-viral vectors. There are several requirements for developing a device small ehought to efficiently leave the vasculature and enter cells to perfome multiple tasks [1]. There are some limitations yet to be resolve for their use in the gene delivery studies, namely, potential toxicity, low transfection efficiency. Undeniaby, shape and novel properties at the nanoscale are esential to fullfill the needs. More over, selected Nanostructure has to have the ability to incorporate genetic materials such as plasmid DNA, RNA, and siRNA. Considering that non-viral vectors tested so far show very low efficiency of gene delivery [2], there is a need to develop and test nanoparticles with novel and precised physicochemical propierties (Figure 1).

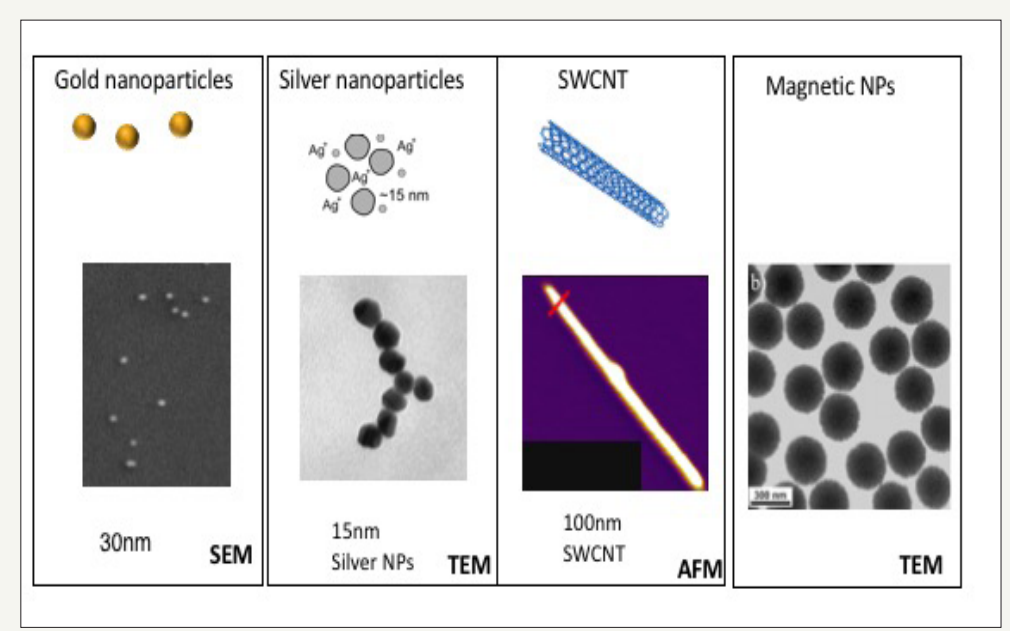

Figure 1: Inorganic NPs genereted in Trigueros' group as backbone nano-gene-delivery systems.

Emerging nanomaterials with versatile properties such as optical, piezoelectric, thermal, electrochemical, enzyme-mimicking etc. are still being developed. With the proper combination of novel properties, nanotechnology will bring to us new and exciting tools to explore the design of innovative, efficient, accurate, stable and low toxicity nano-gene-delivery vectors [3]. It is easy to imagine, that further developments on nanotechnology, nanomaterials and nano-gene-delivery will, undoubtedly, make a significant impact on biomedical research and translational medicine.

\section{References}

1. Blanco E, Shen H, Ferrari M (2015) Principles of nanoparticle design for overcoming biological barriers to drug delivery. Nat Biotechnol 33(9): 941-951. 
2. Lah NAC, Samykano M, Trigueros S (2016) Nanoscale metal particles as nanocarriers in targeted drug delivery system. J Nanomed Res 4(2): 00086.
3. Garcia-Guerra A, Dunwell TL, Trigueros S (2018) Nano-scale gene delivery systems: current technology, obstacles, and future directions. Curr Med Chem 25(21): 2448-2464.
(C) (9) Creative Commons Attribution 4.0

For possible submissions Click Here
Submit Article

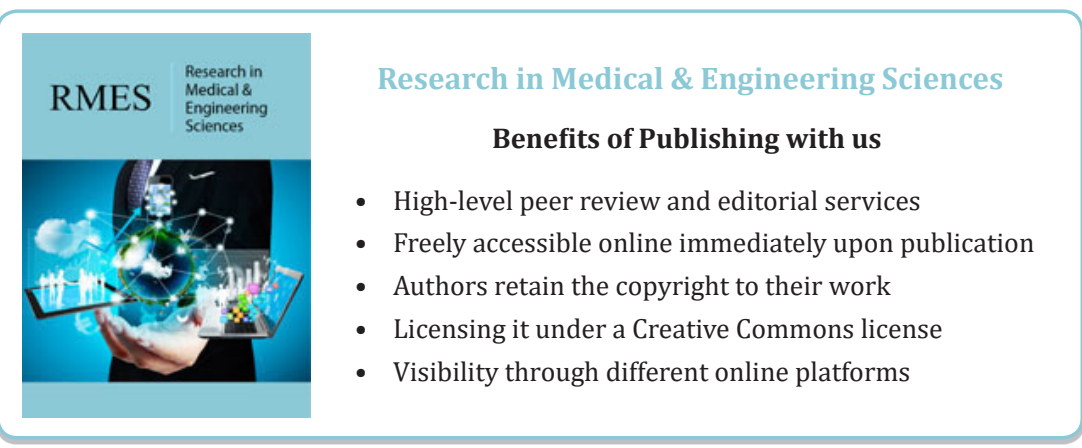

